\title{
Which Dimensions Should Matter for Capabilities? A Constitutional Approach
}

\section{Francesco Burchi, Pasquale De Muro \& Eszter Kollar}

To cite this article: Francesco Burchi, Pasquale De Muro \& Eszter Kollar (2014) Which Dimensions Should Matter for Capabilities? A Constitutional Approach, Ethics and Social Welfare, 8:3, 233-247, DOI: $10.1080 / 17496535.2014 .932415$

To link to this article: https://doi.org/10.1080/17496535.2014.932415

\section{(c) 2014 The Author(s). Published by Taylor \& Francis.}

\section{冓 Published online: 17 Jul 2014.}

Submit your article to this journal ๘

Џلll Article views: 340

Q View related articles $\circlearrowright$

View Crossmark data $\nearrow$

7 Citing articles: 5 View citing articles ¿ 


\title{
Which Dimensions Should Matter for Capabilities? A Constitutional Approach
}

\author{
Francesco Burchi, Pasquale De Muro and \\ Eszter Kollar
}

\begin{abstract}
Multidimensional theories of well-being are locked into a debate about value judgment. They seek to settle which dimensions should matter for measurement and policy, and, more importantly, on what grounds to decide what should matter. Moreover, there is a gulf between theory and practice, given that measurement and policy are rarely rooted in a coherent ethical framework. Our paper engages in the debate concerning the legitimate grounds for selecting dimensions. Combining Amartya Sen's capability approach and John Rawls' method of political constructivism, we explore whether the constitution and its public culture can be used as an ethically sound informational base for selecting dimensions, and if so, why. We apply this 'constitutional approach' to the Italian case with the aim of deriving a set of publicly justifiable dimensions of wellbeing. It is a long-standing Constitution with broad public consultation at its base, which still enjoys a wide consensus. We seek to show why there is a need for more ethically sound methodological approaches to measuring well-being, pointing out the advantages of the constitutional approach, and how it may enrich the work of practitioners engaged in the policies of well-being.
\end{abstract}

Keywords: Well-being; Capability Approach; Political Constructivism; Constitution; Italy

Francesco Burchi a Senior Researcher at the German Development Institute since April 2013. He holds a $\mathrm{PhD}$ in Development and Environmental Economics and is currently the coordinator of the 'Human Development' module of the M.A. in Human Development and Food Security, Roma Tre University. He has several publications in peer-reviewed international journals, and in books and reports in the following topics: human development, well-being, hunger and food security, inequality, nutrition, and gender equality. Correspondence to: Francesco Burchi, German Development Institute, Department 'Sustainable Economic and Social Development', Tulpenfeld 6, Bonn, Germany. Email: francesco.burchi@ die-gdi.de. Pasquale De Muro (Ph.D., M.Sc.) is professor of Human Development Economics at the Department of Economics of Roma Tre University, Italy. His recent publications and research activities concern Development Theories and Policy, Human Development and Capability Approach, Poverty and Well-Being Analysis, Hunger and Food Security. Pasquale De Muro, Roma Tre University, Department of Economics, Rome, Italy. Email: pasquale.demuro@uniroma3.it.

Eszter Kollar is a Research Fellow at the Chair of International Political Theory, at the Normative Orders Excellence Cluster, Goethe University Frankfurt. Her current research explores the various ways in which social and global health inequalities raise problems of justice, with a particular focus on medical brain drain and prenatal equality of opportunity. Beyond these topics she has also published on the political conception of global justice, Rawlsian constructivism, and relative deprivation and self-respect. Eszter Kollar, Goethe University Frankfurt, Frankfurt am Main, Germany, Email: eszter.kollar@normativeorders. net 


\section{Introduction}

Theories of multidimensional well-being are locked into a debate about value judgment. They seek to settle which dimensions should matter for measurement and policy, and, more importantly, on what grounds to decide what should matter, given that various criteria have been proposed and are used in the literature. Moreover, there is a gulf between theory and practice, given that measurement and policy are rarely rooted in a coherent ethical framework. As Grusky and Kanbur $(2006,12)$ write, 'economists have not reached consensus on the dimensions that matter, nor even on how they might decide what matters'. As this paper shows, the economic debate needs to be guided by philosophical theories on well-being and justification in order to settle those questions.

Our paper engages in the debate concerning the legitimate grounds for selecting dimensions. Combining Sen's ([1985] 1999, 1999) capability approach and Rawls' (1993) method of political constructivism, we explore whether the constitution and its public culture can serve as an ethically suitable informational base for selecting dimensions, and if so, why. Then, we apply this 'constitutional approach' to the Italian case in an attempt to derive a set of publicly justifiable dimensions of well-being. It is a long-standing Constitution with broad public debate at its base, which still enjoys a wide consensus. We seek to show why there is a need for more ethically sound methodological approaches to measuring well- being, pointing out the advantages of the constitutional approach, and how it may enrich the work of practitioners engaged in the policies of well-being. In fact, selecting and prioritising wellbeing domains is an inescapable preliminary step in the design of policies, the allocation of public resources and the measurement of well-being.

Using the capability approach has two implications. First, the concept of wellbeing has a clear and precise meaning: "Well-being" is concerned with a person's achievement: how “well” is his or her "being"?' (Sen [1985] 1999, 5); more precisely, a person's well-being can be seen as an evaluation of the vector of his or her functionings (12), where 'a functioning is an achievement of a person: what he or she manages to do or to be' (10). We will use this definition of well- being. ${ }^{1}$ Although Sen's concept of well-being may appear abstract at first glance, it has a very practical meaning and is not difficult to operationalise: Functionings, in fact, are various aspects of people's life ('beings' and 'doings'), such as 'being well nourished', 'living in a decent house', or 'participate in the life of the community', and they can be also measured and assessed.

Second, the capability approach sees well-being from two different perspectives: Not only the above mentioned 'well-being achievement' but also the 'wellbeing freedom', i.e. the freedom to achieve well-being (Sen 1993). A person's capability includes both the former and the latter: The two perspectives are

1. For an in-depth discussion of Sen's definition of well-being and human development, see Burchi and De Muro (forthcoming). 
distinct but interrelated. This distinction will be particularly relevant when we analyse the Italian Constitution.

This paper is divided into four sections. The next section presents a brief critical review of the literature on the choice of dimensions that are used for measuring well-being. In the subsequent section, we seek to provide an argument in support of political constructivism as the appropriate method of justification in pluralist societies that can also be used for selecting well-being dimensions. Then, by using a constructive interpretation of the Italian Constitution, we try to detect possible dimensions for Italy that have a sound ethical foundation. In the last part we present our conclusions.

\section{Approaches to Selecting Dimensions}

Well-being dimensions are domains of people's lives. According to Alkire (2002), they must be human ends-thus endowed with intrinsic value-, while at the same time specific and vague, i.e. clear and expressed in such a way as not to be valid only in a very local context-and complete, as to encompass all human values. Moreover, they should not overlap substantially. Given this comprehensive definition of well-being (as well as poverty and quality of life) dimensions, how can we select them? How can we do it coherently through the capability approach here endorsed?

Amartya Sen $(1993,2004)$ has argued in favour of a deliberative exercise for the selection of relevant capabilities. Such an exercise depends on the specific purpose of the study and on the local context. That is why, according to him, it does not make sense to have a pre-determined list. The list might be different depending on whether we want to evaluate a project, to assess poverty at the macro-scale, to compare countries or to focus on a community. Moreover, the process is itself a fundamental aspect, not just the outcome, i.e. the set of dimensions finally selected. In fact, Sen stresses the distinction between 'comprehensive outcomes' (those that also involve the process that has generated them) as opposed to 'cumulative outcomes' (which only focus on the contents of the final list).

Thus, both choosing and ranking capabilities is a value judgment (Sen [1985] $1999,1987)$ that researchers should make explicit and, where possible through a democratic deliberative process. Unfortunately, most of the empirical studies on multidimensional well-being and poverty, including those rooted in the capability approach, have failed to explain why they chose certain dimensions and which selection criteria they have used. ${ }^{2}$ We argue that the selection of dimensions is a crucial step in understanding well-being in a society and developing measures and tailoring policies, and as such, must pass the test of moral scrutiny.

2. See, for example, Burchi and Gnesi (forthcoming) for the limits of some indicators of well-being elaborated for Italy. 
The fact that Sen has not provided any details on how to select domains and on which methods would better fit his viewpoint on this matter, has been criticised. ${ }^{3}$ Robeyns (2003) has been the first to identify a set of guidelines to choosing dimensions. Her four criteria help to reduce selection bias resulting from the social positioning of the researchers, as factors like gender, religion or age may influence the outcome of the process. According to Robeyns (2003), the list should first of all be explicitly formulated, and thus clear, open to discussion and properly justified and defended. Then, the methodology used to generate it should be justified in view of the objective of the evaluation (see below for the existing methods reviewed by Alkire [2008]). Third, the list should meet the criterion of 'different levels of generality', based on which a researcher should start with an ideal, theoretically robust list, and only at a later stage move to a feasible one based on data and resource availability. Finally, the ideal list should be exhaustive and not capable of further reduction. These procedural methods should be interpreted as 'a sort of "check and balance"' (Robeyns 2005, 206).

Alkire has classified the methods employed in empirical works. Though she explicitly refers to dimensions of poverty, the same categories are also valid for dimensions of well-being. In the existing literature on multidimensional poverty, we encounter five different approaches to/methods of dimension selection (Alkire 2008). The first approach is based on existing data. Here, the existence of data forms the only guiding criterion. Often, scholars do not engage in a debate on relevant dimensions, but just pick dimensions and variables for which data are available.

The second approach selects dimensions on the basis of normative assumptions. The paramount example is Maslow's (1948) pyramid of needs. Nussbaum's (2000) list of ten central capabilities fits into this group, as she builds on the Aristotelian idea of a 'good life' to determine what people value across cultures. A series of empirical studies have been conducted based on her list (Anand, Hunter, and Smith 2005; Di Tommaso 2006). The existence of a public consensus is the basis of the third approach. A set of dimensions can be the outcome of 'some arguably legitimate consensus building process at one point in time, and are relatively stable, thus not expected to be iterative or subject to ongoing participatory evaluation' (Alkire 2008, 10). Examples are the Millennium Development Goals and the Universal Declaration of Human Rights.

Alkire labels the fourth approach as 'ongoing deliberative participation'. Through focus groups, group discussions and other participatory techniques it is possible to draw out people's actual values. This method can, for example, be combined with normative assumptions, based on the researcher identifying an initial list as a starting point for a participatory exercise. ${ }^{4}$

3. Robeyns (2003) calls this the 'weak' criticism as opposed to a 'strong' one addressed by Nussbaum (2000) and others. These scholars argue that in order to operationalise the capability approach, it is necessary to generate a list of basic capabilities: Providing the tools to choose among the different potential dimensions would not be sufficient.

4. See Biggeri and Libanora (2011) for an innovative method of selecting children's relevant capabilities, which fits into this approach. 
Finally, the choice of dimensions can be made by looking at previous empirical analyses. Some scholars rely on empirical surveys, such as the World Value Survey that show the values that are important across cultures.

Each of these approaches, taken individually, has relevant flaws, when examined in light of Robeyns' criteria and our own considerations. The scope of this paper does not allow us to elaborate exhaustively on objections, but some brief remarks must be made. First, the existence of empirical data might be a feasibility constraint, but it lacks moral quality. Second, justifying well-being dimensions based on any particular normative view might be a worthwhile philosophical exercise, but runs into difficulty when proposed as a basis of public justification in a pluralist society. We cannot reasonably expect persons, who do not share the same moral assumptions, to endorse them. Some even think that proposing them as public criteria is devoid of respect for persons with diverging moral or religious views. Third, the deliberative ideal has its own virtues, but the normative validity of its outcome requires conditions of deliberation that are often difficult to put into practice. Fourth, taking public consensus (or public opinion) as grounds for justification suffers from conservatism or a status quo bias. The fact the people or societies have come to endorse or agree on a set of moral values does not in itself lend it moral authority. What needs to be specified is whether the moral characterisation of widely shared or publicly endorsed values is possible and if so, how. Using some of these five approaches together, as is often done, may reduce their weaknesses, but may also introduce inconsistencies, especially if the criteria are not explicitly discussed.

Our paper joins the debate at this point. It elaborates on a yet unexplored method of justification, at least insofar as the debate on poverty and well-being dimensions is concerned. In what follows, we explore Rawls' method of political constructivism and how it could be employed in the justification of well-being dimensions based on public ideals embedded in the constitution and the public life of a society. It could be seen as a qualified public consensus view, which is an adjustment to its traditional variant with a moral characterisation of public ideals as grounds for justification. The departure from the consensus view is crucial in two respects. First, political constructivism takes an alleged public consensus as its starting point, and not as the end point of justificatory reasoning. Second, a key point of departure is that its moral quality does not lie in the (fact of) consensus per se, but the moral reasons that select publicly accessible values as starting points of justificatory reasoning.

\section{Political Constructivism}

This section aims to provide some theoretical support for political constructivism as the appropriate method of justifying public norms in pluralist democracies.

Political choices and institutions, often implicitly, rely on a chain of justificatory reasons for their validity in the public debate. What reasons support a certain policy choice as opposed to another? Which normative assumptions does the data 
rely on? Which aspects of human life are taken into account in measuring? These are some of the questions any political proposal will need to answer and make transparent in its appeal for legitimacy.

A fundamental normative constraint on public life is that the reasons we appeal to in justifying political actions aim to provide reasons for others. In a pluralist society where people reasonably disagree about fundamental values this is no easy task. Foundationalist approaches to justification derive normative principles from intuitions that are taken to be self-evident or universally valid axiomatic truths. Their communitarian and postmodern critics take reasons to be historical artefacts and characteristics of particular ways of life. When faced with the 'fact of pluralism' and moral disagreement, they both conclude, in surprising agreement, that authoritative reasons are incompatible and incommensurable, hence disagreement about institutional norms is a persistent aspect of modern life (Roberts 2007, 3).

Political constructivism is a method of justification driven by a concern with the suitable grounds for justifying normative principles under the constraint of moral pluralism. It has been, most notably, developed in the later work of John Rawls (1993), which takes on the challenge of the 'fact of reasonable pluralism' and demonstrates that against the background of reasonable disagreement, a shared normative point of view of justice is possible. Rawls' A Theory of Justice (1971) has been widely criticised for relying on a particular, Kantian, idea of the person, based on which he had laid out his original position. His revised political conception of justice has aimed at accounting for the diversity of citizens' moral commitments by acknowledging that its justification cannot select any particular conception of the good as privileged. A normative argument that aims at establishing regulative principles in a pluralist context should make 'reference to a standard that all citizens have reason to accept' (Scanlon 2003, 160). Rawls' solution is to start from ideas latent in the 'public political culture', which can be 'seen as a fund of implicitly shared ideas and principles' (Rawls 1993, 14). What Rawls means by public culture is the 'political institutions of a constitutional regime and the public traditions of their interpretation' (13). Constructing justice on ideas present in the public culture, the hope is that it can avoid controversial claims of truth about the human good and, hence, can come to be endorsed from a variety of moral perspectives. What needs to be emphasised is that the political standards that the constructivist argument yields are limited in scope to the political domain it is intended to regulate.

Rawls' political constructivist starting points are his conception of citizen and society as embedded in the public culture of a constitutional democracy. As James (2005) has pointed out, what Rawls is doing is not a mere sociological description. Rather, it is a 'constructive interpretation' (285), a morally laden characterisation of a democratic regime on the basis of moral ideals deeply rooted in its public culture. What needs to be grasped is the normative aim and purpose of democracy according to its self-understanding, i.e. which resonates with the mutual recognition of its members. In Rawls' theory, society is characterised as a scheme of cooperation among free and equal citizens, who 
cooperate for the mutual provision of social goods on terms that are justifiable to all. This 'model conception' informs the justificatory argument at various stages and serves as a general background, against which the requirements of justice are constructed.

In this paper we argue that Rawls' method can be fruitfully employed in a justificatory argument towards a political conception of capabilities. More precisely, when selecting dimensions of capabilities that are to provide the normative material for measuring well-being in context, reasoning about the relevant dimensions should start from the public political culture. Like Rawls, we propose the constitutional essentials and their interpretative practice as the source of implicitly shared ideas in a political community and from there work towards a notion of well-being capable of being publicly shared. Resting the justification of well-being dimensions on political grounds and avoiding any reference to comprehensive moral views, the hope is that the resulting public standard could be widely endorsed, despite reasonable disagreement about what 'the good life' actually is. Such a political conception could, then, serve as the basis for publicly reasoning about policy goals and measuring well-being. ${ }^{5}$

An important line of criticism concerns itself with the status quo bias of political justification. Critics object that a form of justification that is founded on widely shared political ideals amounts to affirming as justice what people accept (or have accepted) as just. A different version of this criticism holds that insofar as institutions came about through historical struggles, oppression and often violence, an idea of justice constructed on political grounds perpetuates historical injustice. Both readings depict a rather conservative outlook concerning the role and purpose of normative theorising. Political philosophy seems to collapse into the politics of satisfying preferences or re-affirming the institutional status quo.

One way to respond is by pointing out how exactly political constructivism departs from a broadly understood public consensus view. For the sake of discussion we can draw together under one heading various procedures or methods (consensus or convergence) that are thought to yield actual agreement with regards to citizens' normative commitment. In this sense Klosko's (2000) 'method of convergence' which draws on empirical survey data to identify political principles citizens actually agree to, can be addressed together with the public consensus view, pointing out their main difference from political constructivism. The public consensus or survey method takes the well-being dimensions the procedure yields at face value and attributes their normative quality to the fact that people have come to an agreement that is relatively

5. Nussbaum (2007) has an extensive study where she uses the capabilities approach as a normative test for the US constitution to see how well it does in securing basic entitlements grounded in her core group of capabilities. She does not, however, use the constitution in the justificatory argument for selecting the dimensions of capabilities. 
stable. If agreement is the reason why people should care about certain wellbeing dimensions, this indeed has conservative implications. Taking people's current attitudes or beliefs about well-being amounts to accepting as justice what people believe to be just. People's beliefs, however, can be misguided or wrong for various reasons.

Political constructivism can avoid this problem for two reasons. First, there is a crucial normative distinction to be made between an actual and a possible agreement; between what actual citizens will agree to here and now taking their beliefs, preferences and attitudes as a given, and what can be justified to reasonable citizens upon reflection and informed argument. Political constructivism takes the allegedly widely shared values to be mere starting points for normative reflection. It then places them under a systematic method of moral reflection that provides a hypothetical or pro tanto justification that citizens then have to examine from within their systems of belief for a full justification (Freeman 2007). The constructivist argument starts from fundamental ideas embedded in the political culture. However, it does not stop at taking stock of the main ideas embodied in the constitutional text. Instead, it takes a critical stance and presents them in their most compelling light. In political constructivism there is a significant theoretical space between publicly embedded values and normative principles, where systematic moral and political reasoning takes place. One can, in such a way, develop a critical distance from the dominant interpretation of the norms embedded in society. Onora O'Neill has forcefully argued in defence of practical reasoning based on social norms, that the norms embedded in a social practice 'underdetermine action' and are 'open to interpretation and reinterpretation'. They 'constitute a revisable basis for reasoning rather than a set of fixed and timeless conclusions'. 'Norm-based practical reasoning is not, then, unavoidably conservative' $(2000,22)$.

The second, and key, departure is that political constructivism does not take constitutional values as the basis of justification, just because it enjoys a 'sort of consensus'. It is not the fact of consensus that motivates the view, but the underlying normative reason that selects public justification as the suitable one for a pluralist society. Reasoning from public ideals that are allegedly shared is an attempt to take pluralism seriously, by referring to arguments that people have reason to care about despite their diverging moral commitments (Scanlon 2003). It amounts to treating people in justification with equal respect. Thus political constructivism is not political all the way down, but there is a moral reason that selects the method of justification in the first place. In short, the main difference between the survey method and our Rawlsian approach is the moral criterion that selects the method as the appropriate one. It is not consensus but an idea of equality in justification. ${ }^{6}$

6. There is a limit to how much pluralism the Rawlsian justificatory method can accommodate in that it appeals to reasonable citizens and relies on their faculty of reason, their ability to examine their own ends and to revise them upon due reflection. For a similar concern with Sen's democracy as public reason see Argenton and Rossi (2013). 
In what follows, we take Rawls' method as a basis for reasoning about selecting dimensions of well-being in a concrete socio-political context. We examine the Italian Constitution as a source of public ideals that provide the starting point of 'constructive interpretation'. The idea is that selecting dimensions of capabilities in such a way could serve as a reasonable public basis of justification that could guide the measurement and policy of well-being in Italy, and could enrich our more general understanding of well-being.

\section{Well-being and the Italian Constitution}

The Italian Constitution was written by the Constituent Assembly between June 1946 and December 1947, and promulgated on 27 December 1947.

There is a wide consensus among scholars (Onida 2007; Carlassare 2012) about the fact that this Constitution has been the result of a broad and rich public debate among the many diverse political cultures (Christian, socialist, communist, conservative, liberal, republican and others) that were represented in the Constituent Assembly, elected in June 1946 by 89.1 per cent of voters, and that all of those cultures contributed to produce the document, though to a varying extent. $^{7}$

The Italian Constitution consists of three main sections: 'Fundamental Principles', 'Part I. Rights and Duties of Citizens', 'Part II. Organisation of the Republic' ${ }^{8}$ In this paper, we will restrict our focus to the first two sections, for two reasons:

(1) Only those sections are relevant to the purposes of this work, as the third section concerns the organs of the Republic (Parliament, President, Government, Judicial Branch, Local organs, etc.);

(2) While the first two sections have never been changed (and there has never been any significant appeal or attempt to change them), the third section has undergone some important revisions. The fact that from 1948 until today the first two sections of the Constitution have not been modified at all is evidence that they have enjoyed, and still enjoy, a very broad and persistent consensus among the Italian public.

Given the cultural and social context of the 1940s, it is not surprising that the Italian Constitution never mentions the word 'well-being' or anything like it. We show that this lack does not mean that the 'Constituent Fathers' were not concerned about what we would today call 'well-being'. In fact, although a

7. This does not mean that the political discussion took place without cultural conflicts and strong divergences on certain specific aspects. However, the predictable disagreements did not result in a cultural and political clash, and a civilised high-profile compromise was eventually found. This was possible because of the civic momentum that characterised the young Italian Republic soon after the end of Fascism and World War II.

8. Unless explicitly indicated, the citations from the constitution are from an official edition in English (Camera dei Deputati 2007). 
comprehensive and multifaceted concept of well-being is not explicitly envisioned in the constitution, it is possible to find many clear and significant references to a number of fundamental well-being dimensions, labelled as 'rights' and/or 'freedoms'. With reference to Sen's definition of 'well-being' mentioned above, we will consider only those rights and freedoms that are directly and specifically related to well-being achievement and well-being freedom. We will omit other rights that could indirectly influence the comprehensive picture, as being beyond the scope of this paper.

Before pointing out well-being dimensions in the text of the Constitution, one cannot but notice an extraordinary affinity between one of the fundamental principles of the Constitution and the 'Human Development and Capability Approach' (HDCA). The second paragraph of Art. 3 refers to the 'full development of the human person'. According to Giorgio La Pira, ${ }^{9}$ one of the most authoritative fathers of the Constitution, this is the ideal at which the Constitution aimed. Likewise, 'human development ... is about creating an environment in which people can develop their full potential' (UNDP 2001, 9). ${ }^{10}$ Therefore, the Italian Constitution and the HDCA, although crafted in very different times and milieus, have a common foundation.

Starting with the Fundamental Principles (Art. 1-12), it is very significant that the first article of the Constitution states 'Italy is a Democratic Republic, founded on work'. Hence, the first well-being dimension that is cited is 'work'. Further on, Art. 4 reinforces this priority ('... the right of all citizens to work ...'). A number of other articles are, then, dedicated to this dimension. In section 2, on the 'Rights and Duties of Citizens', there is a subsection on 'Economic Rights and Duties', which includes as many as six articles about work: Art. 35 ('The Republic protects work ...'), Art. 36 (Work remuneration and hours), Art. 37 (Work of women and minors), Art. 38 (Social security and protection), ${ }^{11}$ Art. 39 (Free trade unions), Art. 40 (The right to strike).

Given the position of 'work' in the text (Art. 1) and the numerous articles dedicated to it, there are good grounds for arguing that this is the dimension of well-being valued most highly in the Italian Constitution. This is not a surprise, given the important role of socialists, communists and social Christians in the Constituent Assembly. Furthermore, considering the protections and safeguards provided by the above mentioned articles, it is not just 'work' per se that is considered valuable, but rather 'decent work', to use a concept coined by ILO (1999).

9. Interview given in the 1950s and recently broadcast by RAI (Italian public Television) on 30 June 2008. Available at http://www.rai.tv/dl/RaiTV/programmi/media/Contentltem-29950599-0443-46af-

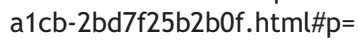

10. This concept is extensively discussed by Mahub ul Haq (1995), founder of the Human Development Report.

11. It is interesting to notice that in the official English version, the Italian words 'mantenimento e assistenza sociale' (literally, 'maintenance and social assistance') have been translated as 'welfare support'. 
Two other fundamental dimensions of well-being can be detected in section 2's subsection on 'Ethical and social rights and duties':

- Art. 32 is about 'health' and 'medical care', and is the only one about this dimension;

- Art. 33 and 34 are about 'education'.

Art. 33 makes a point of 'arts and science', that can also be found in Art. 9 of section 1 about 'the development of culture and ... research'. Although citizens' access to or enjoyment of culture and knowledge are not explicitly cited, there is a certain attention to the cultural dimension of well-being.

A further group of articles is about 'participation', in its various forms:

- in section 1, Art. 3: 'actual participation of all workers in the political, economic and social organization of the country'12,

- civil participation, in section 2, subsection I (Title I. Civil rights and duties): Art. 17 on 'the right to assemble', Art. 18 on 'the right to form associations', Art. 21 on people's 'right to express freely their ideas' (including the press);

- economic participation, in section 2, subsection III (Title III. Economic rights and duties): Art. 41 on free private economic initiative, Art. 45 on co-operative enterprises and artisanal work, Art. 46 on workers' collaboration in the management of enterprises;

- political participation, in section 2, subsection IV (Title IV. Political rights and duties): Art. 48 on the right and duty to vote, Art. 49 on free association in parties, Art. 50 on citizens' petitions; Art. 51 on citizens' eligibility.

These articles clearly show that civil, economic and political participation receives much attention, similar to 'work'. There also exists a strong connection between the latter and economic participation.

This short review shows that at least seven fundamental well-being dimensions are clearly embedded as public ideals in the constitution. According to the amount of space dedicated to each of them, we could rank them in the following way: (1) decent work; (2) political, (3) civil and (4) economic participation; (5) education; (6) health; (7) culture, arts and science.

It is also evident that a number of important dimensions, which can be found in the extensive literature on well-being or in other constitutions, are missing. Just to give some significant examples of missing dimensions, let us consider the OECD Better Life Initiative (OECD 2011) and the Italian Equitable and Sustainable Well-Being (BES) (CNEL and ISTAT 2013). Both include 'environment' (i.e. living in

12. This is our own translation of the text and not the official one, as the latter is not faithful: In translating the Italian word effettiva, they use the 'false friend' effective, while the right translation is actual. 
a clean and safe environment), ${ }^{13}$ 'safety' and 'community/social relationships'; the OECD also includes 'housing'.

It is difficult to understand why there is no reference to such important dimensions in the Italian Constitution. Of course, one reason can be the age of the document (about 65 years). This may, for instance, explain the absence of the environmental dimension, as in the 1940s-especially in Italy-there was much less awareness about ecological problems than today. However, this cannot explain the absence of the 'housing' dimension, which has always been a major problem in contemporary Italy and an aspect of well-being highly valued by Italians. ${ }^{14}$ Possibly, ensuring full and decent employment to all workers was then considered a sufficient condition for achieving a number of other basic functionings, such as housing and social inclusion (which is related to 'community/social relationships'). Recent extensive evidence of working poor and even of working homeless suggests that work alone is not a sufficient condition to ensure decent housing or social inclusion.

The lack of any explicit reference to some important dimensions should not be considered a reason for rejecting the Italian Constitution as an appropriate informational base for choosing the relevant well-being dimensions. In fact, as Sen writes, 'the problem of valuation is not ... one of an all-or-nothing kind' $(1999,78)$ : The incompleteness-also typical of the capability approach-should not be a source of embarrassment. Therefore, we can utilise the seven dimensions from the Constitution pointed out above as a core, minimum list, or starting, open-ended list of fundamental dimensions, which may be integratedif and when it is necessary-with further ones selected according to analogous, equally consistent criteria.

From this perspective, there are at least three possible roads to follow. First, the European one: Given the long process of integration of Italy firstly into the European Common Market, then into the European Community and finally into the European Union, there already is a consolidated jurisprudence and case law according to which it is legitimate to refer to European treaties for subjects not explicitly considered in the Italian Constitution. The second one is the international road: As the Italian Constitution recognises the role of international treaties, conventions and agreements in various articles, one can refer to treaties ratified by Italy as an additional source of relevant well-being dimensions. Last, but not least, according to Art. 2 (initially proposed by Giorgio La Pira in 1947), 'The Republic recognizes and guarantees the inviolable rights of the person'. Although the Universal Declaration of Human Rights was adopted by the UN General Assembly on 10 December 1948-that is just one year after the Italian Constitution-, the reference to the 'inviolable rights of the person' made

13. Actually, in the Constitution there is a short reference to the safeguard of 'natural landscape', but this is just one very limited aspect of the broader environmental dimension.

14. Evidence of this value is the fact that the home has always been the number one investment for Italians and, as a matter of fact, the rate of home ownership in Italy is among the highest in the EU-15 (Source: Eurostat). 
by Art. 2 also makes it possible to consider that Declaration as a possible source of valuable well-being dimensions for Italy.

\section{Conclusions}

Our paper has argued that Sen's capability approach provides a fertile basis on which to approach policy-making about well-being. We have further argued that existing methods of selecting well-being dimensions, especially those that rely on existing data or the actual preferences of citizens, are problematic from a normative point of view and that Rawls' political constructivism provides a promising solution to those problems. We have proposed the Constitutional Approach to select dimensions and analysed the Italian Constitution to exemplify how well-being dimensions might be arrived at and provide the basis of a public discussion. The reasons in favour of Rawls' method support the constitutional essentials as suitable normative starting points, while the capability approach and its conception of well-being provides moral guidance for their interpretation. Sen's notion of well-being, then, is a conceptual frame for the publicly grounded dimensions of well-being, and its role will become even more evident in the choice of indicators. Its aim is to provide a politically grounded ethical solution to a political problem.

However, our approach should not be seen as limited to countries with written constitutions. Public ideals may be detected in basic institutions and the public political culture that interprets them, as well as in oral traditions of fundamental values, as is often the case in Africa, where no such texts exist. Moreover, the approach should not be seen as limited to the Italian state, or nation states in general. Conceiving of constitutions in the broad sense, as basic rules and fundamental values of social and political cooperation, we may start from similarly suitable public ideals in the global political context, such as the international doctrine of human rights, in order to work out the global dimensions of well-being and capabilities. What remains as a difficulty and a question yet to be settled, is how to draw the moral limits of suitable constitutions. Constitutions are very different, some more adequate than others, and some involve public ideals that are deemed morally unacceptable. Deciding whether a specific constitution is a good starting point for public morality may require a set of procedural and substantive criteria.

\section{Acknowledgements}

This paper is an outcome of the National Research Project (PRIN) 'Measuring Human Development and Capabilities in Italy: methodological and empirical issues' co-funded by the Italian Ministry of Education, University and Research (MIUR). The authors would like to thank the participants in the PRIN workshop organized in Pescara, April 2013, and the participants in the 'Human Development and Institutions' session at the EAEPE Conference in Paris, November 2013. 


\section{References}

Alkire, S. 2002. “Dimensions of Human Development." World Development 30 (2): 181-205. doi:10.1016/S0305-750X(01)00109-7.

Alkire, S. 2008. Choosing Dimensions: The Capability Approach and Multidimensional Poverty. MPRA paper, 8862. http://mpra.ub.uni-muenchen.de/8862.

Anand, P., G. Hunter, and R. Smith. 2005. "Capabilities and Well-Being: Evidence Based on the Sen-Nussbaum Approach to Welfare." Social Indicators Research 74 (1): 9-55. doi:10.1007/s11205-005-6518-z.

Argenton, C., and E. Rossi. 2013. "Pluralism, Preferences, and Deliberation: A Critique of Sen's Constructive Argument for Democracy." Journal of Social Philosophy 44 (2): 129-145. doi:10.1111/josp.12022.

Biggeri, M., and R. Libànora. 2011. "From Valuing to Evaluating: Tools and Procedures to Operationalize the Capability Approach." In Children and the Capability Approach, edited by M. Biggeri, J. Ballet, and F. Comim, 79-106. London: Palgrave.

Burchi, F., and C. Gnesi. Forthcoming. "A Review of the Literature on Well-Being in Italy: a Human Development Perspective." Forum for Social Economics.

Burchi, F., and P. De Muro. Forthcoming. "Measuring Human Development in a High-income Country: A Conceptual Framework for Well-being Indicators." Forum for Social Economics.

Camera dei Deputati. 2007. The Constitution of the Italian Republic. Rome: Segreteria Generale, October 25.

Carlassare, L. 2012. Nel segno della Costituzione. La nostra carta per il futuro. Milano: Feltrinelli.

CNEL and ISTAT. 2013. Il benessere equo e sostenibile in Italia. Rome: CSR.

Di Tommaso, M. L. 2006. "Measuring the Well-Being of Children Using a Capability Approach: An application to Indian Data." Working Papers 05/06, Centre for Household, Income, Labour and Demographic economics (CHILD), Italy.

Freeman, S. 2007. "The Burdens of Public Justification: Constructivism, Contractualism, and Publicity.” Politics, Philosophy \& Economics 6 (1): 5-43. doi:10.1177/1470594X07073003.

Grusky, D. B., and R. Kanbur. 2006. Poverty and Inequality. Redwood City: Stanford University Press.

Haq, M. 1995. Reflections on Human Development. New York: Oxford University Press.

ILO (International Labour Organization). 1999. "Report of the Director-General: Decent Work." Report presented at the International Labour Conference, June, 87th Session, Geneva.

James, A. 2005. "Constructing Justice for Existing Practice: Rawls and the Status Quo." Philosophy \& Public Affairs 33 (3): 281-316. doi:10.1111/j.1088-4963.2005.00034.x.

Klosko, G. 2000. Democratic Procedures and Liberal Consensus. New York: Oxford University Press.

Maslow, A. H. 1948. “'Higher' and 'Lower' Needs.” Journal of Psychology 25 (1): 433-436. doi:10.1080/00223980.1948.9917386.

Nussbaum, M. 2000. Women and Human Development: The Capabilities Approach. Cambridge: Cambridge University Press.

Nussbaum, M. 2007. "Constitutions and Capabilities: Perception against Lofty Formalism." Harvard Law Review 121 (4): 4-97.

O'Neill, O. 2000. Bounds of Justice. Cambridge: Cambridge University Press.

OECD (Organisation for Economic Co-operation and Development). 2011. How's Life? Measuring Well-being. Paris: OECD.

Onida, V. 2007. La Costituzione. Bologna: Il Mulino.

Rawls, J. 1971. A Theory of Justice. Cambridge, MA: The Belknap Press of Harvard University Press. 
Rawls, J. 1993. Political Liberalism. New York: Columbia University Press.

Robeyns, I. 2003. "Sen's Capability Approach and Gender Inequality: Selecting Relevant Capabilities." Feminist Economics 9 (2-3): 61-92. doi:10.1080/1354570022000078024.

Robeyns, I. 2005. "Selecting Capabilities for Quality of Life Measurement." Social Indicators Research 74 (1): 191-215. doi:10.1007/s11205-005-6524-1.

Roberts, P. 2007. Political Constructivism. London: Routledge.

Scanlon, T. 2003. "Rawls on Justification." In Cambridge Companion to Rawls, edited by S. Freeman, 139-167. Cambridge: Cambridge University Press.

Sen, A. K. [1985] 1999. Commodities and Capabilities. Delhi: Oxford University Press.

Sen, A. K. 1987. The Standard of Living. Cambridge: Cambridge University Press.

Sen, A. K. 1993. "Capability and Well-Being." In The Quality of Life, edited by M. Nussbaum and A. K. Sen, 30-53. Oxford: Clarendon Press.

Sen, A.K. 1999. Development as Freedom, Knopf, New York.

Sen, A. K. 2004. "Capabilities, Lists, and Public Reason: Continuing the Conversation." Feminist Economics 10 (3): 77-80. doi:10.1080/1354570042000315163.

UNDP. 2001. Human Development Report 2001: Making New Technologies Work for Human Development. New York: Oxford University Press. 